\title{
EVALUATION OF IMPLANT-ASSISTED MANDIBULAR OVERDENTURE WITH NEW METAL TO METAL INTERFACE ATTACHMENT SYSTEM (IN VITRO STUDY)
}

\author{
Rania E. Ramadan ${ }^{\prime *} B D S$, Faten S. Mohamed ${ }^{2} P h D$, Mohamed A Gepreel ${ }^{3} P h D$
}

\begin{abstract}
INTRODUCTION: A well-constructed two-implant-assisted mandibular overdenture can be a successful treatment option for completely edentulous patients as it helps improving the oral function and patient satisfaction through elimination of the fear of dislodgment during speech or mastication. Various attachment systems can be used for retaining mandibular overdentures such as bar, ball and socket, OT equator and locators. A new attachment system with metal to metal interface named Titach has evolved. During mastication, loads are transferred to alveolar bone surrounding the implants.

OBJECTIVES: This study was done to compare the stress transmitted to peri-implant tissues of implant-assisted mandibular overdenture using two different attachment designs; Titach attachment and locator attachment.

MATERIALS AND METHODS: A completely edentulous epoxy resin mandibular model was used in which two parallel dental implants were inserted at the canine region bilaterally. Sixteen mandibular implant-assisted overdentures were constructed forming two groups; each with different attachment design. Group I received 8 pairs of Titach attachment, while group II received 8 pairs of locator attachment. The difference in stress distribution was measured using strain gauges and compared between the two studied groups. Vertical load and oblique load $\left(30^{\circ}\right.$ and $\left.45^{\circ}\right)$ of 50 and $100 \mathrm{~N}$ using the universal testing machine were applied bilaterally on the central occlusal fossae of mandibular first molars.

RESULTS: There was no significant difference between group I and II upon application of vertical loading 50, $100 \mathrm{~N}$ and $30^{\circ}$ oblique loading $50 \mathrm{~N}$. However, group I showed lower strain values upon application of $30^{\circ}$ oblique loading $100 \mathrm{~N}, 45^{\circ}$ oblique loading $50 \mathrm{~N}$ and $100 \mathrm{~N}$.

CONCLUSIONS: Titach attachment with metal to metal interface showed less strain values with favourable stress distribution when compared to zest anchor locator attachment with nylon interface for implant-assisted mandibular overdenture.

KEYWORDS: implant-assisted overdenture, locator, Titach, strain gauges
\end{abstract}

1. Demonstrator of Removable prosthodontics, Faculty of Dentistry, Alexandria University.

2. Professor of Removable Prosthodontics, Faculty of Dentistry, Alexandria University.

3. Associate Professor of Material Science and Engineering, School of Innovative Design Engineering, Egypt- Japan University of Science and Technology (EJust).

*Corresponding author:

E-mail: raniaelsayed392@gmail.com

\section{INTRODUCTION}

The prosthetic management of edentulous patients has long been a major challenge for dentistry. It has been proven that implant-assisted overdentures are one of the best treatment options in prosthetic rehabilitation of edentulous patients. They satisfy the patient's expectations, improve quality of life with their long term serviceability and predictable outcomes. In addition, they have many beneficial effects like preservation of bone volume, improved retention, stability, function, proprioception and comfort (1).

The glossary of implant dentistry, defined implantassisted prosthesis as any prosthesis that is completely or partly supported by an implant or implants (2).

According to the McGill consensus, it had been suggested that an overdenture with two implants is the first choice of treatment in the edentulous mandible. This was also reiterated by the York Consensus $(3,4)$.

The design of implant-assisted overdentures varies according to the method of attachment and amount of support to be desired from implant and ridge mucosa. Various attachments have been advocated for retaining overdentures to implants. The commonly used types are bars, ball and sockets, locators, magnets, OT equators and telescopic crowns (1).
The LOCATOR attachment (Zest Anchors, Inc, homepage, Escondido, CA, USA) was introduced in 2001. It is considered as universal hinge, as it is compatible with the majority of available implant systems. It consists of male and female parts; the male part is made of nylon which is incorporated in a metal housing that is found in the fitting surface of the overdenture. It has several advantageous characteristics, including resiliency and self-alignment (making it easy for the patient to align and seat the prosthesis in a repeatable path of insertion) (5). Furthermore, it is characterized by dual retention (internal and external thus, providing greater degree of retention) (6$8)$, ease of replacement of the nylon-retentive inserts $(9,10)$, maintenance of oral hygiene (11), and a low-profile (7). A next-generation LOCATOR attachment system (LOCATOR R-Tx Removable Attachment System) corrects up to $30^{\circ}$ correction per implant and $60^{\circ}$ between implants (5).

A new attachment system named Titach prosthetic system (Implanova, Dental Evolutions Inc., Beverly Hills, CA, USA) was developed as a solution for implant-assisted overdentures. It can be used for indications requiring up to $33^{\circ}$ divergence for a single implant, or $66^{\circ}$ divergence 
between contralateral implants. It requires a vertical clearance of $4.5 \mathrm{~mm}$ and a diameter of $6 \mathrm{~mm}$ to accommodate the cap. It employs a metal to metal interface between the cap and the abutment unlike nylon interface such as Zest anchor locator system. The cap has vertical slots to allow its opening on engaging the abutment. It includes a special medical grade silicone sleeve that acts as a block-out during pick-up of the cap. After the pick-up, this silicone sleeve is cut into half and inserted between the cap and the cap housing so that it locks under the outer edge of the cap. It allows for up $0.2 \mathrm{~mm}$ of vertical cushioning, permitting compression of the mucosa during function and parafunction and gradual seating of the prosthesis. Moreover, each attachment is able to resist between 7-10 lbs of force (12).

Current techniques used to evaluate the biomechanical load on implants comprise the use of photoelastic stress analysis $(13,14)$, two-dimensional (2D) or threedimensional (3D) finite element stress analysis (15), and strain-gauge analysis (16).

A strain gauge is a device used to measure strain on an object. It is a small electric resistor that under slight deformation alters the resistance created in their current. It measures the deformation of an object where it is applied. The captured electrical signal is sent to a data acquisition board, turned into a digital signal, and read by the computer. The most common type consists of an insulating flexible backing which supports a metallic foil pattern. The gauge is attached to the object by a suitable adhesive, such as cyanoacrylate (17).

\section{MATERIALS AND METHODS}

A ready-made set of completely edentulous maxillary and mandibular models made of epoxy resin (Ramses medical products factory, Alexandria, Egypt) were used. The width of the mandibular model was $7.5 \mathrm{~mm}$ at the canine region. The epoxy resin was covered with mucosa simulating material made of flexible polyurethane of $1.5 \mathrm{~mm}$ thickness. These models were duplicated into maxillary and mandibular stone models for fabrication of overdentures.

\section{Fabrication of the mandibular overdentures}

Maxillary and mandibular trial denture bases with wax occlusion rims were constructed on the duplicated stone models and mounted on mean value articulator; on which maxillary and mandibular acrylic teeth were arranged and adjusted.

The inter-canine distance in the mandibular arch was $22 \mathrm{~mm}$ (each was $11 \mathrm{~mm}$ from the midline) which simulates the distance between two natural canines (18).

Sixteen mandibular trial denture bases were constructed on the duplicated stone model. The same size mandibular acrylic teeth (size 22, Acrostone cross-linked acrylic teeth, Cairo, Egypt) were arranged on all the trial denture bases utilizing the opposing maxillary trial denture and the same mounting to ensure standardization of all the mandibular overdentures.

Flasking and packing using heat-cure polymethyl methacrylate (Acrostone heat-cure material, Cairo, Egypt) were performed for the sixteen mandibular trial denture bases. Finishing and polishing were done for all the overdentures using the conventional method.

\section{Acrylic drilling template fabrication and implant installation}

A light-cure acrylic resin drilling template was fabricated over the finished overdenture using a vacuum-forming machine to ensure the precise location of implant drilling at the canine region bilaterally.

The sequence of drilling was performed as follow: cortical drill, pilot drill, body drill (core drill), head drill and finally body drill again to wash out debris. The parallelism of the two implants was checked by the paralleling pin (Implanova, Dental Evolutions Inc.,Beverly Hills, CA, USA during drilling the second implant.

Two implants (Implanova, Dental Evolutions Inc.,Beverly Hills, CA, USA) of $10 \mathrm{~mm}$ length and $3.5 \mathrm{~mm}$ diameter each were inserted in the drilled holes using torque wrench. The primary stability was $35 \mathrm{~N}$.

\section{Pick-up of Titach attachment [group I]}

Two Titach attachments were screwed to each of eight mandibular overdentures under torque of $20 \mathrm{~N}$ using torque wrench. The silicone sleeve was placed on the cap making sure that the top of the silicone sleeve is below the upper edge of the cap and it does not cover the retentive fins. The cap-sleeve assembly was placed over the abutment firmly until a definite seated position. The sleeve must cover the entire abutment neck that is extruding from the gingival area in order to prevent the acrylic resin from locking around the abutment (Figure 1).

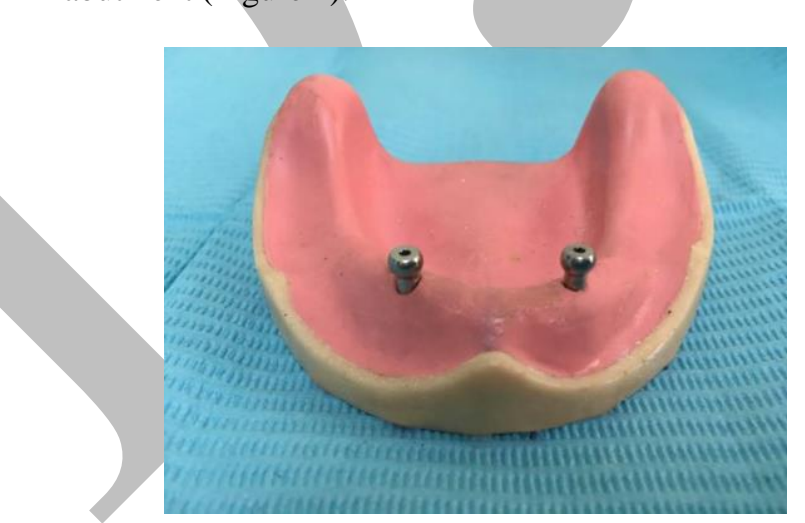

Figure (1): Showing Titach attachment.

The overdenture was placed over the model. The position of the attachments was marked by a marker in order to be relieved until the overdenture was fully seated. Two holes were made in the lingual surface of the overdenture corresponding to the position of the attachments to allow escape of excess self-cure acrylic resin that is used for pickup of the attachments' caps.

A separating medium was applied on the model and monomer was applied on the holes. Cold-cure polymethyl methacrylate was mixed. When the mix reached the dough stage, it was placed in the fitting surface of the overdenture. The overdenture was seated over the model to pick-up the attachments' caps. After setting, the silicone sleeve came out with the overdenture. Then by scalpel; the protruding part of the sleeve from the cap was removed. Finally, finishing and polishing of the acrylic resin was done (Figure 2). 


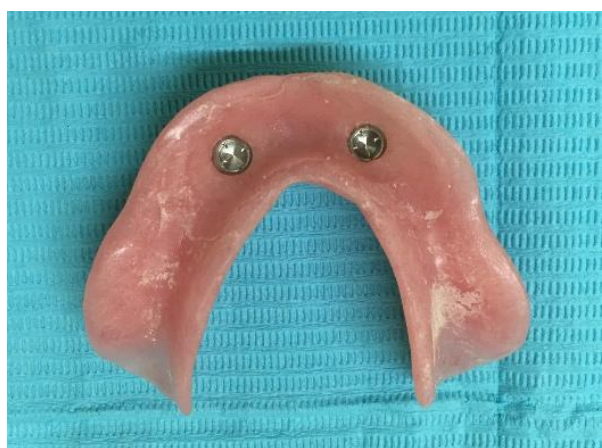

Figure (2): Showing fitting surface of the overdenture with Titach's caps.

\section{Pick-up of zest-anchor locator [group II]}

Two zest anchor locator attachments of $3 \mathrm{~mm}$ collar height were screwed to each of the other eight mandibular overdentures under torque of $20 \mathrm{~N}$ using torque wrench (Figure 3). A white block out spacer ring was placed around each abutment. Then, a denture cap with a black processing male was placed onto each abutment and was pressed down to ensure engagement of the abutment.
Preparation of the model and installation of strain gauges (19)

Eight self-protected linear strain gauges (KFG-1-120-C111L1M2R, KYOWA strain gages, Tokyo, Japan) of a gauge factor $2.13 \pm 1 \%$, a gauge length $1 \mathrm{~mm}$ and a gauge resistance of $119.6 \pm 0.4 \Omega$ were used in this study.

Eight channels were prepared in the epoxy model to receive the strain gauges. Four channels were prepared at the labial, lingual, mesial and distal aspect of each implant. The channels were at the crestal region, parallel to the long axis of the implant and there was $2 \mathrm{~mm}$ thickness of epoxy resin between the strain gauge and the implant. The channels were prepared with flat walls especially the wall parallel to the implant on which the strain gauge will be placed.

Strain gauges were installed on their corresponding prepared sites in the epoxy resin model to measure the strain in peri-implant tissues (Figure 5). A Cyanoacrylate adhesive (CC-33A, Kyowa, Japan) was used to cement the strain gauges parallel to the long axis of each implant. The strain gauges were left for 24 hours to ensure complete setting of the adhesive.

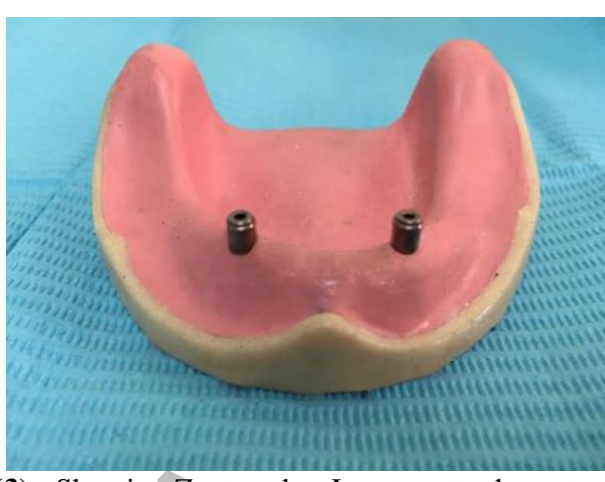

Figure (3): Showing Zest-anchor Locator attachment.

The areas where the denture will need to be relieved were marked to allow space for the caps to be picked up. Lingual vent windows in the denture were made to visualize full seating and for excess material to vent. The denture caps were dried. Cold-cure polymethyl methacrylate was mixed and placed into the relief areas of the denture and then the overdenture was seated over the caps and was left until the material set. Then, the overdenture was disengaged from the abutments. Finally, Finishing and polishing to the acrylic resin was done.

The black processing male was removed and substituted by clear locator nylon insert of $5 \mathrm{lbs}$ retention force using the locator core tool (Figure 4).

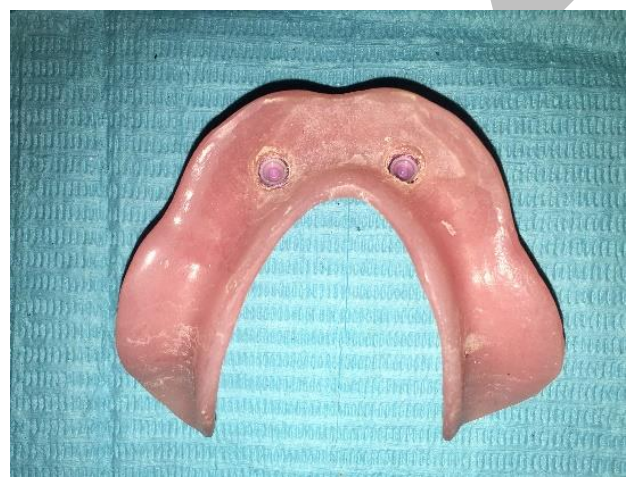

Figure (4): Showing fitting surface of overdenture with locator attachment of clear nylon insert.
Figure (5): Showing installation of strain gauges in their prepared channels.

The wires of the strain gauges were embedded in specially prepared channels which were created in the base of the model to avoid accidental displacement of the wires that may affect the accuracy of the readings. All the wires were labelled indicating the surface to be measured. The wire terminals of the 8 strain gauges were connected to a multichannel strain meter.

\section{Loading application and strain measurement}

A universal testing machine (Mecmesin, Multi Test5-XT $(5 \mathrm{KN}), \mathrm{USA})$ connected to a computer was used to apply vertical and oblique $\left(30^{\circ}, 45^{\circ}\right)$ loading. The load was applied in a compression mode through two metal rods with crosshead speed set at $10 \mathrm{~mm} / \mathrm{min}$ (Figure 6)

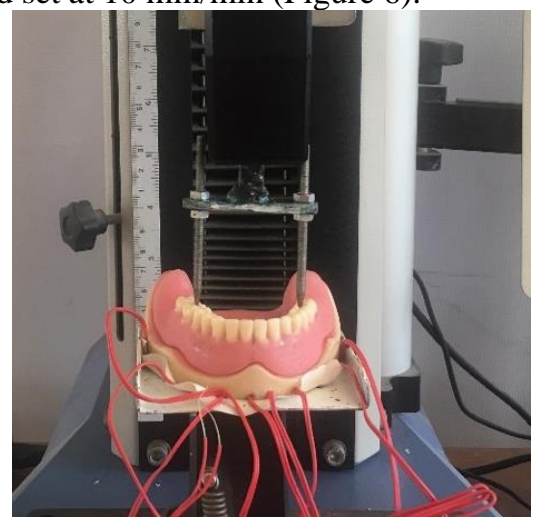

Figure (6): Showing application of vertical loading. 
The load application was in the form of bilateral loading, the load was delivered through metal rods directed to the right and left central occlusal fossae of the first molars. The magnitude of load was $50 \mathrm{~N}$ and $100 \mathrm{~N}$ which simulates the average amount of biting force of completely edentulous patient on an implant-assisted overdenture (2022).

All the strain gauges were zeroed and calibrated prior to loading. The strain gauge sensors were connected to a strain meter (Data Logger model TDS-150, Japan) that is connected to another computer to measure the strains that result from the applied load.

This procedure was repeated for every overdenture in group I and II under the same conditions. Five minutes were left between each loading as a period of rest to allow for heat dissipation from the strain gauge sensors (23).

Due to the use of variable materials with different modulus of elasticity (young modulus), it was difficult to obtain an equation to convert strain to stress. Moreover, there is direct correlation between strain and stress; when strain increases, this means there is high stress (24).

\section{Statistical analysis}

Data were collected and entered into the personal computer. Statistical analysis was performed using statistical packages for social sciences (SPSS), version 20 (IBM Corp., Armonk, NY). The Kolmogorov-Smirnov test was used to verify the normality of distribution of the quantitative data. The tests used were Mann Whitney test and Wilcoxon signed ranged test because data were not normally distributed, to compare between the two groups. The $5 \%$ was chosen as the level of significance (25).

\section{RESULTS}

Stress analysis at peri-implant tissues of mandibular implant-assisted overdenture by measuring the strain distribution using strain gauges was compared between the two studied groups as shown in table 1 .

The values of strains developed after load application in the labial, lingual, mesial and distal aspects of the implants in both right and left implant were summed and compared between the two studied groups

There was no statistically significant difference in the value of the sum of strains developed at peri-implant tissues in right and left implants in mandibular implant-assisted overdenture between group I (Titach) and group II (Locator) after application of vertical loading $50 \mathrm{~N}$ and $100 \mathrm{~N}$ with $\mathrm{p}=$ 0.189 and $\mathrm{p}=0.184$ respectively.

Also, there was no statistically significant difference in the value of the sum of strains between group I (Titach) and group II (Locator) after application of $30^{\circ}$ oblique loading $50 \mathrm{~N}$ with $\mathrm{p}=0.668$.

However, there was statistically significant difference in the value of the sum of strains between group I (Titach) and group II (Locator) after application of $30^{\circ}$ oblique loading $100 \mathrm{~N}, 4^{\circ}$ oblique loading $50 \mathrm{~N}$ and $100 \mathrm{~N}$, as group I showed lower strain value with median $=13.28$, 33.22 and 39.90 respectively as compared to group II whose median $=48.45,76.82$ and 103.67 respectively and $\mathrm{p}=$ $0.024, \mathrm{p}=0.026$ and $\mathrm{p}=0.001$ respectively.
Table (1): Showing the values of all the strains $(\varepsilon)$ in both right and left implants between the two studied groups.

\begin{tabular}{|c|c|c|c|}
\hline & $\begin{array}{c}\text { Group I } \\
(16 \text { Titach) } \\
(n=8)\end{array}$ & $\begin{array}{l}\text { Group II } \\
(16 \text { Locator) } \\
(n=8)\end{array}$ & $\begin{array}{l}\text { Test of } \\
\text { significance } \\
p \text { value }\end{array}$ \\
\hline $\begin{array}{l}\text { Vertical loading } 50 \mathrm{~N} \\
\text { Min-Max } \\
\text { Mean } \pm \text { SD } \\
\text { Median (IQR) } \\
\end{array}$ & \begin{tabular}{|c|}
$0.92-78.3$ \\
$27.78 \pm 22.0$ \\
$21.56(9.20-43.72)$ \\
\end{tabular} & $\begin{array}{c}0.92-88.32 \\
25.22 \pm 27.06 \\
16.29(2.07-35.9)\end{array}$ & $\begin{array}{l}Z_{\text {arw }}=1.314 \\
P=0.189 \mathrm{NS}\end{array}$ \\
\hline $\begin{array}{l}\text { Vertical loading } 100 \mathrm{~N} \\
\text { Min-Max } \\
\text { Mean } \pm \text { SD } \\
\text { Median (IQR) }\end{array}$ & $\begin{array}{c}1.84-142.6 \\
42.48 \pm 41.10 \\
22.48(6.63-69.92)\end{array}$ & $\begin{array}{c}0.92-141.6 \\
30.88 \pm 41.41 \\
32.50(2.76-42.37)\end{array}$ & $\begin{array}{l}Z_{\text {ANW }}=1.327 \\
P=0.184 \mathrm{NS}\end{array}$ \\
\hline $\begin{array}{l}30^{\circ} \text { oblique loading } 50 \mathbf{~} \\
\text { Min-Max } \\
\text { Mean } \pm \text { SD } \\
\text { Median (IQR) }\end{array}$ & $\begin{array}{c}0-397 \\
71.96 \pm 106.32 \\
26.54(2.76-82.33)\end{array}$ & $\begin{array}{c}0.92-345.18 \\
59.09 \pm 83.45 \\
35.70(3.64-53.68)\end{array}$ & $\begin{array}{l}Z_{\text {(ANW }}=0.429 \\
P=0.668 \mathrm{NS}\end{array}$ \\
\hline $\begin{array}{l}30^{\circ} \text { oblique loading } 100 \mathrm{~N} \\
\text { Min-Max } \\
\text { Mean } \text { SD } \\
\text { Median (IQR) } \\
\end{array}$ & $\begin{array}{c}0.92-506 \\
71.57 \pm 125.63 \\
13.28(3.60-62.11)\end{array}$ & $\begin{array}{c}0.92-891 \\
120.12 \pm 211.21 \\
48.45(8.66-107.0)\end{array}$ & $\begin{array}{c}Z_{\text {Paw }}=2.260 \\
P=0.024^{*}\end{array}$ \\
\hline $\begin{array}{l}45^{\circ} \text { oblique loading } 50 \mathrm{~N} \\
\text { Min-Max } \\
\text { Mean } \pm \text { SD } \\
\text { Median (IQR) }\end{array}$ & $\begin{array}{c}0.92-439 \\
101.14 \pm 139.85 \\
33.22(19.40-85.56)\end{array}$ & $\begin{array}{c}14.44-428.72 \\
125.28 \pm 123.37 \\
76.82(29.44-194.12)\end{array}$ & $\begin{array}{c}Z_{\text {arw }}=2.226 \\
P=0.026^{\circ}\end{array}$ \\
\hline $\begin{array}{l}45^{\circ} \text { oblique loading } 100 \mathrm{~N} \\
\text { Min-Max } \\
\text { Mean } \pm \text { SD } \\
\text { Median (IQR) }\end{array}$ & $\begin{array}{c}4.60-1004 \\
137.81 \pm 236.55 \\
39.90(19.32-112.54)\end{array}$ & $\begin{array}{c}18.40-609.70 \\
199.64 \pm 206.58 \\
103.67(47.84-346.6)\end{array}$ & $\begin{array}{c}Z_{\text {Q avw }}=3.324 \\
P=0.001^{*}\end{array}$ \\
\hline
\end{tabular}

$\mathrm{n}$ : Number of overdentures

Min-Max: Minimum - Maximum

SD: Standard deviation

IQR: Inter-quartile range

*: Statistically significant ( $\mathrm{p} \leq 0.05)$

NS: Statistically not significant $(p>0.05)$

\section{DISCUSSION}

In this study, the completely edentulous models were prepared from epoxy resin material which has an appropriate elastic modulus for a bone analogue material (approximately $20 \mathrm{GPa}$ ) (26).

Only two implants were chosen to be placed as it was reported by McGill and York consensus who reported that an overdenture with two implants is the first treatment option in the edentulous mandible $(3,4)$.

Implants were placed bilaterally in the anterior mandible especially the canine region. The anterior area was chosen as many studies concluded that this area showed high implant success rate when loaded by overdentures (27).

Each implant was $10 \mathrm{~mm}$ length and $3.5 \mathrm{~mm}$ diameter. The $10 \mathrm{~mm}$ length was chosen as it is considered as an adequate length to obtain optimum stress distribution around the implants. According to Georgiopoulos et al (28), implant length from $10 \mathrm{~mm}$ to $14 \mathrm{~mm}$ resulted in strain reduction on bone tissue during immediate and delayed implant loading. However, implants shorter than $10 \mathrm{~mm}$ did not alter the strain field. Moreover, it was reported that there should be at least $1 \mathrm{~mm}$ of bone at buccal and lingual walls at the crest of the potential implant site to ensure sufficient bone thickness and blood supply around the implant for predictable survival. That's why implant with $3.5 \mathrm{~mm}$ diameter was chosen in the model with width of $7.5 \mathrm{~mm}$ at the canine region (29).

There was only one available vertical height of Titach attachment which is $4.50 \mathrm{~mm}$. Thus, the chosen collar height of zest-anchor locator was $3 \mathrm{~mm}$ in addition to the constant height of male seating area of $1.50 \mathrm{~mm}$ with total vertical height $=4.50 \mathrm{~mm}$.

Owing to accuracy in the evaluation of stress distribution and due to difficulty in standardization and repeatability of the obtained values for strain measurement in-vivo, this study was conducted in-vitro to overcome 
limitations of stress analysis studies attempted clinically (30).

The installation of strain gauges was done in prepared flat surfaces in the epoxy resin parallel to the long axis of the implant and perpendicular to the crest of the ridge. It is preferred to bond the strain gauge on completely flat surface to minimize the possibility of obtaining incremental apparent strain that result from mounting the strain gauge on curved surface $(31,32)$.

Moreover, strain gauges were bonded to the crest of the ridge around the implants because peri-implant stresses and bone loss usually initiated at the alveolar crest around the implant's neck and possible overloading could occur from compression of cortical bone at alveolar crest (33).

It was observed that, the average biting force of completely edentulous patients wearing implant-assisted overdentures was in range of 50-100N. Thus, it was selected as the magnitude of load directed to the overdentures (2022).

In this study, the first molar was chosen for loading because maximum occlusal forces are often exerted in this region where there is maximum contraction of the elevator muscles (34). In addition, vertical and oblique static loads were applied bilaterally to the central fossae of first molars. This is in agreement with Tokuhisa et al (22) who mentioned that occlusal force tended to be concentrated around the molar region where the denture showed the largest movement. The load was applied bilaterally to simulate centric occlusion in vivo.

Furthermore, loading was applied vertically parallel to the long axis of the implants and oblique $\left(30^{\circ}\right.$ and $\left.45^{\circ}\right)$. This oblique loading application was done in accordance to Lin et al (35) who reported that forces of mastication are more oblique due to inclination of artificial tooth cusps and strains from oblique forces are more important to be recorded since they are more detrimental than vertical forces.

In this study, there was no statistically significant difference in strain values between both studied groups upon application of vertical loading. This could be attributed to vertical forces that were directed within the long axis of the used implants and attachments which were parallel to each other. In addition, Titach attachment possessed silicone sleeves around the caps that might have allowed stress distribution like the nylon inserts which were incorporated in the locator's caps. There was another explanation for this non-statistically significant difference in strain values which may be related to the favourable character of Titach attachment that allows for up $0.2 \mathrm{~mm}$ of vertical cushioning, permitting compression of the mucosa during function and parafunction loads.

However, there was statistically significant difference between both studied groups upon application of $30^{\circ}$ oblique loading $100 \mathrm{~N}, 45^{\circ}$ oblique loading 50 and $100 \mathrm{~N}$ with favourable strain values using Titach attachment. This could be postulated to the metal to metal interface design of Titach attachment, in addition to the flat occlusal surface of the abutment which proposed to minimize the oblique stresses on peri-implant tissues.

\section{CONCLUSION}

Within the limitations of this study, the following conclusions were obtained:
1-There was no difference in strain values between Titach attachment and Locator attachment upon application of vertical loading for implant-assisted mandibular overdenture.

2- Titach attachment showed less strain values with favourable stress distribution when compared to Locator attachment upon application of oblique loading.

\section{CONFLICT OF INTEREST}

The authors declare that they have no conflicts of interest.

\section{REFERENCES}

1-Kaur P. Implant Supported Overdenture: A Case Report. Periodontics. 2016; 2(2):13.

2-Glossary of implant dentistry III. International congress of oral implantologists; 2017.

3-Feine JS, Carlsson GE, Awad MA, Chehade A, Duncan WJ, Gizani S, et al. The McGill consensus statement on overdentures: mandibular two-implant overdentures as first choice standard of care for edentulous patients. Montreal, Quebec, May 24-25, 2002. Int J Oral Maxillofac Implants. 2002; 17:601-2.

4-Thomason JM, Feine J, Exley C, Moynihan P, Müller F, Naert I, et al. Mandibular two implant-supported overdentures as the first choice standard of care for edentulous patients-the York Consensus Statement.Br Dent J. 2009; 207(4): 185-6.

5-Zest Dental Solutions. http://www.zestdent.com. Accessed March 15, 2018

6-Evtimovska E, Masri R, Driscoll CF, Romberg E. The change in retentive values of Locator Attachments and Hader clips over time. J. Prosthodont. 2009; 18:479-83

7-Büttel AE, Bühler NM, Marinello CP. Locator or ball attachment: a guide for clinical decision making [in French, German]. Schweiz Monatsschr Zahnmed. 2009; 119:901 18.

8-Cakarer S, Can T, Yaltirik M, keskin C. Complications associated with the ball, bar and LOCATOR attachments for implant-supported overdentures. Med Oral Patol Oral Cir Bucal. 2011; 16:e953-9.

9-Chikunov I, Doan P, Vahidi F. Implant-retained partial overdenture with resilient attachments. J Prosthodont. 2008; 17:141-8.

10-Kleis WK, Kämmerer PW, Hartmann S, Al-Nawas B, Wagner W. A comparison of three different attachment systems for mandibular two-implant overdentures: one-year report. Clin Implant Dent Relat Res. 2010; 12:209-18.

11-Ahuja S, Wicks R, Selecman A. Fabrication of new restorations with a consideration of oral hygiene. J Indian Prosthodont Soc. 2016;16:307-10

12-Dental Evolutions Inc. https://www.denvolution.com.

13-Tonella BP, Pellizzer EP, Ferraço R, Falcón-Antenucci RM, Carvalho PS, Goiato MC. Photoelastic analysis of cemented or screwed implant-supported prostheses with different prosthetic connections. J Oral Implantol. 2011; 37:401-10.

14-Tonella BP, Pellizzer EP, Falcón-Antenucci RM, Ferraço R, de Faria Almeida DA. Photoelastic analysis of biomechanical behavior of single and multiple fixed partial prostheses with different prosthetic connections. J Craniofac Surg. 2011;22:2060-3 
15-Geng JP, Tan KBO, Liu GR. Application of finite element analysis in implant dentistry: a review of the literature. $\mathrm{J}$ Prosthet Dent. 2001; 85:585-98.

16-Yoo JS, Kwon KR, Noh K, Lee H, Paek J. Stress analysis of mandibular implant overdenture with locator and bar/clip attachment: comparative study with differences in the denture base length. J Adv Prosthodont 2017; 9:143-51.

17-Assunção WG1, Barão VA, Tabata LF, Gomes EA, Delben JA, dos Santos PH. Biomechanics studies in dentistry: bioengineering applied in oral implantology. J Craniofac Surg. 2009;20(4):1173-7

18-Sinclair PM, Little RM. Maturation of untreated normal occlusions. Am J Orthod. 1983; 83:114-23

19-Dahab I, El-Gendy A, Eltorky I. In vitro stress analysis study of different prosthetic options using single posterior implant for management of mandibular unilateral distal extension saddle. Tanta Dent J. 2015;12:7-15

20-Rismanchian M, Bajoghli F, Mostajeran Z, Fazel A, Eshkevari P. Effect of Implants on Maximum Bite Force in Edentulous Patients. J Oral Implantol. 2009; 35(4):196-200.

21- Porter JA, Petropoulos VC, Brunski JB. Comparison of load distribution for implant overdenture attachments. Int J Oral Maxillofac Implants. 2002; 17(5):651-62.

22-Tokuhisa M, Matsushita Y, Koyano K. In vitro study of a mandibular implant overdenture retained with ball, magnet, or bar attachments: comparison of load transfer and denture stability. Int J Prosthodont. 2003; 16(2):128-34.

23-Cekic C, Akca K, Cehreli MC. Effects of attachment designs on strains around implants supporting overdentures. Quintessence Int. 2007;38:291-7

24-Anusavice KJ, Shen C, Rawls HR. Phillips' Science of Dental Materials. 12th ed.: St Louis, United States: Elsevier Health Sciences; 2013. Chapter 4, Mechanical Properties of Dental Materials; p.48-68.

25-Kirkpatrick LA, Feeney BC. A simple guide to IBM SPSS statistics for version 20.0. Student ed. Belmont, Calif.: Wadsworth, Cengage Learning; 2013.

26-Lee CK, Karl M, Kelly JR. Evaluation of test protocol variables for dental implant fatigue research. Dent Mater 2009; 25(11):1419-25.
27-Stoker GT, Wismeijer D. Immediate Loading of Two Implants with a Mandibular Implant-Retained Overdenture: A New Treatment Protocol. Clin Implant Dent Relat Res. 2011;13(4):255-61

28-Georgiopoulos B, Kalioras K, Provatidis C, Manda M, Koidis P. The Effects of Implant Length and Diameter Prior to and After Osseointegration: A 2-D Finite Element Analysis, J Oral Implantol. 2007;33(5):243-56

29-Misch CE. Contemporary Implant Dentistry. 3rd ed.: St Louis, United States: Elsevier Health Sciences; 2008. Chapter 10, Available Bone and Dental Implant Treatment Plans; p. 178-99

30-Asundi A, Kishen A. A strain gauge and photoelastic analysis of in vivo strain and in vitro stress distribution in human dental supporting structures. Arch Oral Biol. 2000; 45(7):543-50.

31-El-Gendy AA. Micro-strain evaluation of different implant positions supporting mandibular bilateral distal extension partial over denture. Tanta Dental J. 2007; 4(2):39-46.

32-Akca K, Cehreli MC, Iplikcioglu H. A comparison of three dimensional finite element stress analysis with in vitro strain gauge measurements on dental implants. Int $\mathbf{J}$ Prosthodont. 2002; 15(2):115-21.

33-Baggi L, Cappelloni I, Di Girolamo M, Maceri F, Vairo G. The influence of implant diameter and length on stress distribution of osseointegrated implants related to crestal bone geometry: a three-dimensional finite element analysis. J Prosthet Dent 2008; 100: 422-31.

34-Sadowsky SJ, Caputo AA. Stress transfer of four mandibular implant overdenture cantilever designs. J Prosthet Dent. 2004; 92: 328-336.

35-Lin CL, Kuo YC, Lin TS. Effects of dental implant length and bone quality on biomechanical responses in bone around implants: a 3-d non-linear finite element analysis. Biomed Eng. 2005;17:44-9 